hand simultaneously with the image of the object-glass or speculum formed by the eye-piece; the diameter of that image is given at once by the divisions to $\frac{1}{500}$ of an inch, and can be readily estimated to half that value. The arrangement mentioned by "W. R." is no doubt very convenient, and quite adequate for his purpose; but for high powers I should suppose that the comparative coarseness of the engraved lines would make itself much more felt than it is in Mr. Berthon's invention, and the balance of economy is so greatly in favour of the latter in comparison with every contrivance with which $I$ am acquainted, that $I$ have no hesitation in saying that it ought to be in the hands of every amateur who cares to know the magnifying power of his telescope. It may be procured for five shillings, of $\mathrm{Mr}$. Tuck, watchmaker, Romsey.

T. W. WEBB

\section{New Form of Cloud}

ThE kind of cloud described by M. André Poëy (NATURe, Oct. 19,1871, p. 489) is by no means new or rare if I can judge correctly from the figure and explanation. It may often be seen on the lower part of the flank of a great rain or thunder cloud, and appears to arise from the dropping or subsidence of portions of the air heavily loaded with watery particles. My own impression is that it appears when the cloud is about to break up. M. Poëy will find the cloud described in the Philosophical Magazine for July 1857, where the name of droplets is given to the form, and its position in a thunder cloud indicated by a figure.

\section{Spectrum of Blood}

IN my letter, published in the last number of NATURE, I am strangely enough made to say that "we must not rely on the spectrum." This is an error of the printer. The sentence should have been :- "I have always argued that in such inquiries we must not rely on one spectrum, but compare the action of various reagents."

Broomfield, Sheffield, Oct. 28

\section{Earthquake in Burmah}

I HAVE not read in your "Notes" any record of the earthquake which was felt at daylight of the 16th February last in this city, in two successive and gentle but decided shocks, doing no damage, but which, from the files of the Calcutta Englishman of February I8, seems to have been severe to the N.W. of this, extending through Cachar, Silchar, Gowahatty, to Calcutta and Barrackpore.

This earthquake, you will observe, is synchronous with those of the western hemisphere already recorded by you.

Mandalay, Burmah, Sept. I Charles Halsteid

\section{A Plane's Aspect}

I AGREE with Mr. Proctor that the disuse of the term "position" in geometry would be a serious misfortune; happily, however, it is not its disuse, but the prevention of its misuse which is contemplated. I cannot agree with him that "position" is a word "which no one can misunderstand," for his own letter is a striking example of its being misunderstood, either by $\mathrm{Mr}$. Proctor, or by others. "Aspect and slope," he tells us, "indicate two elements, which, together, fix the position " of a plane. Geometers, however, certainly understand, when a plane is said to be given in position, that something more than its aspect and slope may be regarded as known. Parallel planes have necessarily the same slope and aspect, but surely not the same position. To be told that, because its slope and aspect are invariable, the plane of Saturn's rings has a fixed position in space, notwith. standing that the planet moves bodily in its orbit, would scarcely satisfy a student of astronomy accustomed to geometrical precision.

There can be no doubt that "position" is the true English equivalent of the German word "Lage," and that no ambiguity of the kind above indicated could attach itself to the term, had we a suitable English rendering for the word "Stellung." I do not consider the term "aspect" to be perfect as an equivalent for "Stellung," but I have no hesitation in admitting that $\mathrm{Mr}$. Laughton's suggestion is happier than any previous one I can remember. Mr. Proctor declares his intention of opposing the "use of the word 'aspect' in a sense not at present assigned nor properly assignable ;" but when he wrote thus, he had not seen the letter of Mr. Wilson wherein the term " aspect" is very rigidly defined to be the direction of the normal. To me this very facility with which the word "aspect" lends itself to rigid definition, is a groun 1 of objection against it. I have never seen Stellung defined in the manner in which Mr. Wilson has defined "aspect." Von Staudt, in whose admirable writings I first met the word, introduced it thus: "Parallel planes possess something in common, which may be regarded as appertaining to each one of them, and shall be called their 'Stellung;' the 'Stellung' of a plane, therefore, is determined by any plane which is parallel thereto, and two planes have the same 'Stellung' or different 'Stellungen' according as they are parallel to, or intersect one another."

That the term "aspect" is not sufficiently elastic to permit of its taking the place of "Stellung" in the above passage cannot, I think, be well maintained by Mr. Proctor, seeing that he has not himself hesitated to use it in two widely different senses in the following passage of his letter: "I can see no reason why 'aspect' should be regarded in a new and unfamiliar aspect." The expression "aspect of a plane," whether it be retained or not as the equivalent of the "Stellung einer Ebene," appears to me, I confess, to be much too good to be claimed by Mr. Proctor as indicative solely of the direction of the projection of the normal upon a certain plane of reference. I would suggest, in the interest of his twelve excellent books, that he might qualify "aspect," as thus defined, by an appropriate adjective, for the term is there used in a very technical sense indeed, and is not even applicable to all planes. Although Mr. Proctor can assign, for example, a southerly aspect to the face of a roof which has a slope of $30^{\circ}$, he would find some difficulty in describing the aspect of a roof which has no slope at all, whereas Mr. Wilson would without hesitation pronounce its aspect to be vertical.

Athenæum Club, Oct. $3^{\mathrm{I}}$

T. ARCHER HiRst

Ir is due to my friend and your correspondent, Mr. Cecil J. Monro, of Hadley, to state that, to my knowledge, he was in the habit of employing the word "aspect" in this technical sense Iong before the publication of Mr. Laughton's letter, and I should not be surprised to learn that other geometers have used it before Mr. Monro.

I think Mr. Proctor will find few to agree with him in his con. demnation of the word so used. For myself I heartily agree with Mr. Wilson in the welcome he accords to this "old friend with a new face."

Higbgate, N., Oct. 27

C. M. INGLebY

I AM glad to find, by Mr. Wilson's letter in NATURE for October 26, that the word " aspect," which I suggested, is accepted by him as satisfactory; as, in fact, the word wanted. But anuther correspondent in the same number, Mr. Proctor, pertinaciously insists on the superior merit of the word "position," to be used in the particular sense explained by Mr. Wilson in his former letter. In this I conceive Mr. Proctor is entirely wrong.

"In geometrical language "-I quote from Gregory's "Solid Geometry," I 845-" the position of a plane is determined by making it pass through three given points." Mr. Proctor says he "can see no reason why "position' should be dismissed from the position it has so long occupied." No more can I. I would only call his attention to the fact that the meaning which he would assign to the word "position " is quite different from that which has been accepted, in a technical sense, by geometers, and in an everyday sense by everyday people.

Mr. Proctor's special objections to the word "aspect," rest, it seems to me, on a misconception of its meaning and familiar use. We speak of the aspect of a wall, but not of the aspect of a roof, nor of a hill. What the usage amongst builders in respect of roofs may be, I don't know, but geographers almost invariably speak of the "slope" of a hill, as, for instance, the southern slope of the Himalayas. Put into exact language, the aspect of a plane is the direction of its normal ; and as parallel planes have parallel normals, any number of parallel planes have the same aspect, without reference to their position; bat no two planes, parallel or not, can possibly have the same position.

The word "slope" is almost equally inadmissible; in the first place, it refers to some other plane, which is apt to cause 